Brit. J. vener. Dis. (1961), 37, 282.

\title{
SEROLOGICAL TESTS IN 150 CASES OF LEPROSY*
}

BY

\author{
G. L. DAGUET AND J. LANGUILLON
}

\begin{abstract}
Paris
Hansen's disease is considered to be one of the well-known infections which upset serological tests for syphilis in patients in whom there has been no past or current treponemal infection. The reason why lepers are biological false positive (B.F.P.) reactors and why this failure in the specificity of lipoidal reactions occurs remains obscure. The

were examined by the T.P.I., Kolmer, Kline, and Rein-Bossak tests.

The results of the classical tests were so homogeneous that it was only necessary to consider the qualitative response, the quantitative response being derived from the flocculation tests. Only a qualitative T.P.I. test was performed, the quantitative method not being sufficiently reproducible for routine work.
\end{abstract} frequency of false positive reactions is said to be greater in the lepromatous than in the tuberculoid or dimorphous forms of the disease. Examination of sera from lepers by the treponemal immobilization test (T.P.I.), which is the most specific test available, has lent weight to the criticism of the classical tests.

Nelson (1953) studied the sera of 75 patients from the leper colony of Carville, in whom there was no past history and no clinical signs of syphilis, and found that 75 per cent. of the sera gave positive reactions for reagin but that only 16 per cent. were T.P.I. positive. The percentage of positive T.P.I. tests corresponded exactly with the frequency of syphilis in the population under consideration and Nelson concluded that almost 60 per cent. of these lepers were biological false positive reactors. Nelson's conclusions are shared by numerous workers in France and elsewhere.

Such a lack of specificity of the classical tests for syphilis in lepers is, however, surprising if one considers the remarkable specificity and the high degree of sensitivity of these reactions in large groups of the population. It is for this reason that we have undertaken a systematic study of the serological reactions of the patients with leprosy in the Institut Marchoux de Bamako.

\section{Methods}

Sera were collected with sterile precautions at the Institut Marchoux; some were examined on the spot by the Kolmer, Kline, and V.D.R.L. tests and the rest were placed in ampoules and transported to Paris, where they

\footnotetext{
* Paper read at the M.S.S.V.D. meeting in Paris on May 12, 1961
}

\section{Results}

The 150 lepers examined in this study included 87 cases of lepromatous leprosy, 36 cases of tuberculoid leprosy, and 27 cases of dimorphous leprosy.

The Table shows the following facts:

(1) Lepromatous Forms of the Disease.-67 (77 per cent.) of 87 patients had positive reagin tests and positive T.P.I. tests. In the six cases in which only the tests for reagin were positive, the titres were low always either less than or at the most 1 unit in the Kline test. In fourteen cases, any suggestion of treponemal disease was excluded on the basis of the agreement of the negative T.P.I. and classical serological tests and of the absence of clinical signs.

(2) Tuberculoid Forms of the Disease.-32 (89 per cent.) of 36 patients were positive for both reagin and immobilizing antibody. In one case only, a flocculation test was weakly positive, the T.P.I. test being negative. In three cases all the results were negative.

TABLE

RESULTS OF TESTS FOR REAGIN AND THE T.P.I. TEST

\begin{tabular}{l|c|c|c|c|c}
\hline \multicolumn{1}{c|}{$\begin{array}{c}\text { Type of } \\
\text { Leprosy }\end{array}$} & $\begin{array}{c}\text { Number } \\
\text { of } \\
\text { Cases }\end{array}$ & $\begin{array}{c}\text { Reagin }+ \\
\text { T.P.I. }+\end{array}$ & $\begin{array}{c}\text { Reagin }+ \\
\text { T.P.I. }-\end{array}$ & $\begin{array}{c}\text { Reagin- } \\
\text { T.P.I. }+\end{array}$ & $\begin{array}{c}\text { Reagin-- } \\
\text { T.P.I.- }\end{array}$ \\
\hline Lepromatous & 87 & 67 & 6 & 0 & 14 \\
\hline Tuberculoid & 36 & 32 & 1 & 0 & 3 \\
\hline Dimorphous & 27 & 20 & 0 & 1 & 6 \\
\hline Total.. & 150 & 119 & 7 & 1 & 23 \\
\hline
\end{tabular}


(3) Dimorphous Forms of the Disease.-Twenty (74 per cent.) of 27 patients were positive for both reagin and immobilizing antibody. In one case the T.P.I. test was positive but reagin was absent from the serum.

Thus, of the 150 sera examined, 126 (84 per cent.) were positive to tests for reagin and 120 ( 80 per cent.) were positive for immobilizing antibody, the agreement between the two types of reaction being about 95 per cent. It should be added that sixty ( 40 per cent.) of the sera examined were found to be powerfully anticomplementary in the Kolmer test.

\section{Discussion}

The 150 patients under consideration suffered from leprosy of different degrees of severity, type, and duration. They did not show definite clinical signs of treponemal disease and their past medical histories were unknown.

The 95 per cent. agreement between the lipoidal reactions and the T.P.I. test is a strong argument in favour of the specific treponemal origin of the positive reactions. The patients belonged to a population group in which syphilis is present in 35 per cent. of individuals.

This group of patients, in whom it was important to establish or disprove the presence of treponemal infection, makes up about one-third of the total of lepers regularly treated and followed up. Thus, at the Institut Marchoux, the percentage of treponemal disease discovered by serological tests corresponds to that observed amongst the whole population from which these patients are drawn.

Whatever type of leprosy is considered, the percentage of positive serological reactions is the same whether classical lipoidal tests or the T.P.I. test are used.

As is usual on the discovery of cases of latent syphilis, the reagin titres were extremely variable, ranging from a positive test on neat serum to positive tests at dilutions of 1 in 32. These variations are undoubtedly due to differences in the duration of the infection.

The existence of an anticomplementary component in the serum was more frequently encountered in these patients than amongst our European cases, a fact for which various explanations may be put forward:

(a) Hansen's bacillus and the tissues involved by it are antigenic; the serum of lepers contains antigenantibody complexes capable of fixing complement;

(b) A variety of parasitic and viral infections in the patients favour the production of modified globulins capable of preventing the lytic action of complement. This anticomplementary action, when it exists, renders the results of the reactions of haemolysis inconclusive, but it is not powerful enough to prevent the immobilization reaction from reaching its end-point, because in the T.P.I. test the concentration of complement (30 per cent. of undiluted guinea-pig serum) is much stronger than in the classical tests.

(c) The use of cardiolipin antigens with the simple and proven techniques probably reduces the number of false positive reactions.

\section{Summary}

The study of 150 cases of leprosy led us to reconsider the common view that leprosy frequently produces positive serological results in patients without syphilitic infection.

In the 150 patients examined, the agreement between the results of the lipoidal reactions and the treponemal immobilization test reached 95 per cent. The incidence of syphilis amongst these patients was about the same as that in the general population from which they were drawn.

\section{REFERENCE}

Nelson, R. A. (1953). "Le TPI test de Nelson et Mayer". Masson, Paris.

\section{Sérologie chez 150 lépreux \\ RÉSUMÉ}

Les résultats de cette étude nous amènent à reconsidérer les notions classiques selon lesquelles la maladie de Hansen produit très fréquemment des réponses sérologiques positives sans syphilis.

Dans le groupe de 150 malades examinés, la concordance entre les résultats des réactions lipidiques et du T.P.I. atteint $95 \%$. L'incidence de la syphilis chez ces malades est du même ordre de fréquence que dans l'ensemble de la population dont ils sont issus. 